\title{
SUSTENTABILIDADE E PRÁticas SUSTENTÁVEIS: CONCEPÇÕeS DE ALUNOS DE QUINTOS ANOS DO ENSINO FUNDAMENTAL
}

\author{
SUSTAINABILITY AND SUSTAINABLE PRACTICES: CONCEPTIONS OF STUDENTS OF FIFTH \\ YEARS OF FUNDAMENTAL EDUCATION
}

SOSTENIBILIDAD Y PRÁCTICAS SOSTENIBLES: CONCEPCIONES DE ESTUDIANTES DE QUINTO AÑOS DE EDUCACIÓN FUNDAMENTAL

\section{Maira dos Santos Silveira \\ (iD) 9}

Graduada em Ciências Biológicas (UFSM)

mairasantossilveira@gmail.com

\section{Laura Oestreich}

\section{iD 9}

Mestra em Educação em Ciências: Química da Vida e Saúde (UFSM) PPG que atua: Doutoranda em Educação em Ciências: Química da Vida e Saúde (UFSM)

lauraoestreich@hotmail.com

\section{Eduarda Tais Breunig (iD) 9}

Graduada em Ciências Biológicas (UFSM)

Docente na Rede Estadual de Ensino - RS

Mestranda em Educação em

Ciências: Química da Vida e Saúde (UFSM)

dudabreunig@hotmail.com

\section{Andréa Inês Goldschmidt (iD) 9 \\ Doutora em Educação em \\ Ciências: Química da Vida e \\ Saúde (UFSM) \\ Docente na Universidade Federal de Santa Maria, Palmeira das \\ Missões, Laboratório de Ensino \\ Docente Doutora em Educação em \\ Ciências: Química da Vida e \\ Saúde (UFSM) \\ andreainesgold@gmail.com}

\begin{abstract}
Resumo
Esta pesquisa objetivou investigar as concepções prévias de alunos de anos inicias do Ensino Fundamental a respeito de sustentabilidade e práticas/atitudes sustentáveis. A metodologia utilizada foi qualitativa e envolveu 45 estudantes. Foi aplicado um questionário semiestruturado contendo questões abertas e fechadas a fim de diagnosticar as concepções prévias dos alunos. Os dados foram tabulados de acordo com a análise de conteúdo. Os resultados demonstram que os conhecimentos prévios advêm, principalmente, das mídias. Uma quantidade significativa dos alunos desconhece o termo sustentabilidade. Houve um grande reconhecimento acerca das práticas sustentáveis, porém os alunos não foram capazes de perceber a abrangência social dos impactos ambientais. Com isso, entende-se que a abordagem ao tema sustentabilidade deve ser mais contextualizada em sala de aula, no intuito de ampliar os conhecimentos dos alunos e evitar concepções fragmentadas.
\end{abstract}

Palavras-chave: Sustentabilidade. Conhecimentos Prévios. Ensino de Ciências. Anos Iniciais.

Recebido em: 11 de maio de 2021.

Aprovado em: 18 de julho de 2021.

Como citar esse artigo (ABNT):

SILVEIRA, Maira dos Santos et al. Sustentabilidade e práticas sustentáveis: concepções de alunos de quintos anos do ensino fundamental. Revista Prática Docente, v. 6, n. 2, e053, 2021. http://doi.org/10.23926/RPD.2021.v6.n2.e053.id1163 


\section{Abstract}

This research aimed to investigate the previous conceptions of students from early years of elementary school about sustainability and sustainable practices/attitudes. The methodology used was qualitative and involved 45 students. A semi-structured questionnaire containing open and closed questions was applied in order to diagnose the students' previous conceptions. Data were tabulated according to content analysis. The results demonstrate that prior knowledge comes mainly from the media. A significant number of students are unaware of the term sustainability. There was great recognition about sustainable practices, but students were not able to perceive the social scope of environmental impacts. With this, it is understood that the approach to the theme of sustainability should be more contextualized in the classroom, in order to expand students' knowledge and avoid fragmented conceptions.

Keywords: Sustainability. Previous knowledge. Science teaching. Early Years.

\section{Resumen}

Esta investigación tuvo como objetivo investigar las concepciones previas de los estudiantes de los primeros años de la escuela primaria sobre la sostenibilidad y las prácticas / actitudes sostenibles. La metodología utilizada fue cualitativa e involucró a 45 estudiantes. Se aplicó un cuestionario semiestructurado con preguntas abiertas y cerradas para diagnosticar las concepciones previas de los estudiantes. Los datos se tabularon de acuerdo con el análisis de contenido. Los resultados demuestran que el conocimiento previo proviene principalmente de los medios de comunicación. Un número significativo de estudiantes desconoce el término sostenibilidad. Hubo un gran reconocimiento sobre las prácticas sostenibles, pero los estudiantes no pudieron percibir el alcance social de los impactos ambientales. Con esto, se entiende que el abordaje del tema de la sustentabilidad debe ser más contextualizado en el aula, con el fin de ampliar el conocimiento de los estudiantes y evitar concepciones fragmentadas.

Palabras clave: Sustentabilidad. Conocimiento previo. Enseñanza de las ciencias. Primeros años. 


\title{
1 INTRODUÇÃO
}

Atualmente as questões ambientais ocupam lugar de destaque e têm feito parte da pauta de discussões nas mais diversas esferas da sociedade. Para iniciar a discussão sobre a problemática ambiental, há de se conceituar o termo "meio". Para Dias (2000), o "meio" designa o ambiente mais abrangente e sua composição depende da interação dos processos bióticos, antrópicos, econômicos e ecológicos; é condição essencial à vida e à sobrevivência que os organismos não se dissociem das circunstâncias que os cercam. Desse modo, o ser vivo não é um ser independente, é peça de uma grande máquina que só existe estando associado às demais peças.

De acordo com Migliari (2001) o meio ambiente é:

\begin{abstract}
A integração e a interação do conjunto de elementos naturais, artificiais, culturais e do trabalho que propiciem o desenvolvimento equilibrado de todas as formas, sem exceções. Logo, não haverá um ambiente sadio quando não se elevar, ao mais alto grau de excelência, a qualidade da integração e da interação desse conjunto (MIGLIARI, 2001, p. 40).
\end{abstract}

Os problemas ambientais oriundos do modo de vida da sociedade têm sido ampliados e chegado a magnitudes locais bem expressivas, principalmente pelo fato de que a maior parte da população brasileira vive em cidades, o que remete a uma necessária reflexão sobre os desafios para mudar as formas de pensar e agir em torno das questões ambientais, numa perspectiva contemporânea (JACOBI, 2003).

Diante dessa crise instalada surgem as discussões sobre a sustentabilidade, atitudes sustentáveis adequadas e desenvolvimento sustentável. Para Brinsmead e Hooker (2011), as práticas sustentáveis têm por objetivo garantir que os processos sejam preservados e melhorados no espaço. Neste contexto, entende-se que a sustentabilidade busca uma compreensão das condições humanas em relação ao meio ambiente, com o propósito de satisfazer as necessidades da sociedade e sustentar a vida no planeta (KATES et al., 2001; RAVEN, 2002; LAMBIN, 2005), materializada por meio de ações como a reciclagem por exemplo.

Jacobi (2003) afirma que o conceito de desenvolvimento sustentável surge para enfrentar a crise ecológica e está relacionado à crítica ambientalista, ao modo de vida contemporâneo, e se difundiu a partir da Conferência de Estocolmo, ocorrida em 1972. Tal conceito tem como pressuposto a existência da sustentabilidade social, econômica e ecológica. Assim, o mesmo autor aponta que se faz necessário harmonizar os processos ambientais com os socioeconômicos, maximizando a produção dos ecossistemas para favorecer as necessidades 
humanas. Leff (2001) sinaliza que não é possível resolver os crescentes e complexos problemas ambientais e reverter suas causas sem que ocorra uma mudança radical nos sistemas de conhecimento, dos valores e dos comportamentos gerados pela dinâmica de racionalidade existente, fundada no aspecto econômico do desenvolvimento.

Diante desta crise, é emergente a sociedade compreender que suas ações não sustentáveis e a produção descontrolada de resíduos interferem no meio ambiente. Torna-se, assim, urgente a necessidade de uma conscientização, a fim de manejar os recursos naturais de forma racional, para preservar um ambiente saudável. Buscam-se ações em que o ser humano possa refletir sobre essa relação, promover o entendimento de suas concepções e se questionar sobre seu lugar no ambiente, tornando possível a avaliação de suas ações sobre ele (MARIN et al., 2003).

Compreende-se que a questão ambiental exige também um processo de educação voltado à construção de distintos conhecimentos, sendo indispensável ensinar e aprender para, então, colocar em prática ações sustentáveis. Considerando a escola como um dos ambientes mais próximos do aluno, o ensino escolar deve, também, oportunizar reflexões e ações educacionais sustentáveis, contribuindo para a aprendizagem de valores e mudança de atitudes no cotidiano da vida do aluno.

Neste sentido, a Constituição Federal de 1988 fortalece o papel da escola enquanto propulsora de uma educação voltada para o cuidado com o meio ambiente. O referido documento estabelece que é dever do Estado "promover a educação ambiental em todos os níveis de ensino e a conscientização pública para a preservação do meio ambiente" (BRASIL, 1988, art. 225, $\S 1^{\circ}$, inciso VI). De forma semelhante, as Diretrizes Curriculares Nacionais para Educação Ambiental, resolução no 2, de 15 de junho de 2012 discorrem que "as Diretrizes Curriculares Nacionais para a Educação Básica em todas as suas etapas e modalidades reconhecem a relevância e a obrigatoriedade da Educação Ambiental” (BRASIL, 2012).

Igualmente importante é o professor conhecer as percepções ambientais acerca do tema a ser desenvolvido em sala de aula, para que possa compreender não apenas quais são os valores que as crianças atribuem ao meio ambiente, como também para que consiga discutir como as ações antrópicas refletem nele, e a partir de tais reflexões, provocar mudanças na sociedade.

Portanto, investigar essas concepções consiste em uma ferramenta importante nos processos de ensino e de aprendizagem. Ausubel (2003) explica que as concepções prévias, geradas a partir das vivências dos alunos, mesmo que sejam ideias espontâneas e por vezes 
equivocadas, são fundamentais para o processo de desenvolvimento cognitivo e atribuição de significados aos conhecimentos. É por meio da interação entre novos e antigos saberes que ocorre uma mudança do estado inicial dos conhecimentos prévios e, assim, uma aprendizagem significativa. Sobre isso, Leonardi et al. (2018) lembram que é importante os professores perceberem os conhecimentos cotidianos de seus alunos para que, caso constatem que estes estejam em desacordo com os conhecimentos científicos, possam, a partir deles, buscar promover a interação dessas concepções com o novo conhecimento, de modo a corrigir obstáculos de aprendizagem.

Para Ausubel (2003), o conhecimento prévio é o que mais influencia as novas aprendizagens, tornando-se, portanto, a variável mais importante para que a aprendizagem ocorra de forma significativa. O mesmo autor destaca que a aprendizagem se dá a partir do que se sabe, sendo denominado subsunçores. Por isso, nesse caso, o conhecimento prévio pode ser um excelente precursor para a discussão do tema em sala de aula; ao serem ampliadas, essas concepções favorecem a construção de uma visão mais adequada e científica sobre o assunto.

Moreira (2012) explica em seus estudos sobre aprendizagem significativa que a construção dos primeiros subsunçores ocorre por meio de processos de inferência, abstração, discriminação, descobrimentos, representação, envolvidos primariamente em sucessivos encontros do sujeito com o objeto, eventos e conceitos ainda nos primeiros anos de vida.

Santos, Machado e Rizzatti (2019) sinalizam que as crianças já trazem para a sala de aula concepções próprias do mundo, formuladas por meio de suas experiências de vida e, cabe ao professor, enquanto mediador, tecer um fio condutor entre o conhecimento de mundo trazido pelos alunos e os conteúdos científicos que fazem parte do currículo escolar. Porém, isso só se faz possível à medida que se investiga os conhecimentos prévios desses alunos.

Diante disso, o presente trabalho teve por objetivo investigar e analisar as concepções prévias de estudantes dos quintos anos do Ensino Fundamental a respeito de sustentabilidade e práticas/atitudes sustentáveis do dia a dia.

\section{Trajetória Metodológica}

A investigação cujos resultados são apresentados neste trabalho foi realizada com duas turmas do quinto ano das séries iniciais do Ensino Fundamental, totalizando 45 estudantes, de uma escola pública localizada no centro do município de Palmeira das Missões, (RS), durante o segundo semestre de 2019. Os sujeitos tinham faixa etária de 10 a 13 anos, sendo a maioria deles de cor branca ou parda e apresentavam heterogeneidade quanto ao poder aquisitivo. 
A pesquisa teve uma abordagem qualitativa e se baseou na aplicação de um questionário sobre as concepções prévias dos educandos referentes à sustentabilidade e práticas/atitudes sustentáveis. Neves (2015) discute que a pesquisa qualitativa tem o objetivo de revelar os mistérios que permeiam o cotidiano, identificando processos que, muitas vezes, devido ao fato de se tornarem parte da rotina de uma determinada realidade, passam despercebidos. Já o uso dos questionários permite atender aos objetivos da pesquisa, pois são instrumentos que se adequam ao objeto de estudo e são capazes de captar a realidade em cujo contexto é inserido. Parasuraman (1991) destaca que o questionário é um conjunto de questões feito com a finalidade de gerar os dados necessários para se atingir os objetivos esperados.

Desta forma, os alunos foram convidados a participar da pesquisa, assinando juntamente com os familiares um termo de consentimento, para responder um questionário semiestruturado (contendo perguntas abertas e fechadas), o qual foi aplicado individualmente depois de ser realizada a leitura do mesmo para os alunos. O questionário utilizado encontra-se no Apêndice A deste trabalho. Posteriormente os questionários foram recolhidos para análise. A metodologia utilizada para compreender o pensamento discente sobre a temática apresentada baseou-se na Análise de Conteúdo (BARDIN, 2011), pois, por meio dela, tornou-se possível descrever, analisar e interpretar as ideias expressas nas respostas fornecidas pelas questões abertas.

De acordo com Bardin (2011), a categorização é uma operação de classificação de elementos constitutivos de um conjunto por diferenciação e, em seguida, por reagrupamento de acordo com o gênero (analogia). Desse modo, a análise de conteúdo categorial é alcançada por operações de desmembramento do texto em unidades, em categorias, segundo agrupamentos analógicos, e se caracteriza por um processo estruturalista que classifica os elementos, de acordo com a investigação sobre o que cada um deles tem em comum. Ou seja, as categorias são rubricas ou classes, as quais reúnem um grupo de elementos (unidades de registro) sob um título genérico, em razão dos caracteres comuns apresentados por esses elementos. O procedimento inicial implica na decodificação dos dados contidos nos textos com descrição detalhada das ideias, ou estágio descritivo, ou, ainda, análise categorial. Para essa autora, a análise de conteúdo compreende três polos cronológicos: a) a pré-análise; b) a exploração do material e c) o tratamento dos resultados, inferência e interpretação.

Neste trabalho são apresentadas e discutidas as categorias a posteriori, que emergiram da análise das respostas do questionário inicial e que revelam as concepções dos estudantes. Em algumas questões os alunos puderam marcar mais de uma alternativa, de forma que os 
resultados podem ultrapassar a frequência de $100 \%$. Com o intuito de melhor apresentar e discutir os dados, essas informações foram organizadas em tabelas, as quais são apresentadas a seguir.

\section{RESUltados E DISCUSSÃo}

Inicialmente, os estudantes foram questionados se já tinham ou não ouvido falar sobre sustentabilidade (Tabela 1).

Tabela 1 - Reconhecimento da palavra sustentabilidade, para alunos de anos iniciais do Ensino Fundamental de uma escola pública do interior do estado do RS

\begin{tabular}{c|c}
\hline Alternativas & Percentual \\
\hline Sim & 40,0 \\
\hline Não & 35,5 \\
\hline Não tem certeza & 24,5 \\
\hline Total & 100,0 \\
\hline
\end{tabular}

Fonte: Silveira et al. (2021).

Os resultados apontam que $40 \%$ dos alunos reconheceram terem escutado anteriormente àquele momento a palavra sustentabilidade. Porém, um número significativo dos participantes respondeu desconhecer o termo, sendo que $54,8 \%$ deles afirmaram nunca ter escutado ou não ter certeza se já escutou. Em contrapartida, os alunos que já conheciam a palavra indicaram locais formais, não formais e informais como apontamento no reconhecimento da palavra sustentabilidade.

Ao serem questionados sobre os possíveis locais em que já ouviram falar sobre o termo sustentabilidade, os resultados mostraram-se divergentes e são apresentados na Tabela 2.

Tabela 2 - Reconhecimento do local em que ouviu falar sobre sustentabilidade, para alunos de anos iniciais do Ensino Fundamental de uma escola pública do interior do estado do RS

\begin{tabular}{c|c}
\hline Alternativas & Percentual \\
\hline Nunca ouvi falar & 30,3 \\
\hline Na televisão & 19,7 \\
\hline Em casa, com familiares & 16,7 \\
\hline $\mathrm{Na}$ internet & 12,1 \\
\hline $\mathrm{Na}$ escola & 10,6 \\
\hline Livros/Revistas & 10,6 \\
\hline Total & 100,0 \\
\hline
\end{tabular}

Fonte: Silveira et al. (2021).

Destaca-se na Tabela 2, que o reconhecimento da palavra sustentabilidade por meio da comunicação televisiva foi indicado por $19,7 \%$ das respostas; $16,7 \%$ dos alunos disseram ter tido acesso ao termo por meio da família, e 12,1\% através da internet, o que indica espaços não formais e até informais como meios de aprendizagem. Ao iniciar essa discussão, é importante destacar que todos as formas de ensino e de espaços são importantes, mas segundo Gohn (2006), 
três espaços são reconhecidos: formal, não-formal (ou não escolar) e informal. O espaço formal ocorre vinculado às instituições de ensino básico e superior, enquanto que o não-formal pode ocorrer em outros espaços, embora se caracteriza por ser mais difusa e menos burocrática e está centrada no trabalho realizado por educadores sociais. Já o espaço informal se refere à educação construída no conjunto das relações sociais do indivíduo, com a família, com os amigos e com demais sujeitos com que se relaciona.

Assim, Gadotti (2005), lembra que a educação não se limita à escola, de modo que o processo de aprendizagem está vinculado às experiências do cotidiano de cada indivíduo, ou seja, sem se restringir apenas ao âmbito formal, mas sim a realizar-se em todo o contexto social. Marques e Marandino (2018) afirmam que os espaços não formais evidenciam uma prática sociocultural intencional de aprendizagem e construção de saberes, sendo desvinculada do sistema educacional metódico, que ocorre em distintos espaços sociais. Libâneo (2010) corrobora sinalizando que o ensino em espaços informais transcorre baseado na espontaneidade gerada por meio das relações com familiares, amigos, colegas, meios de comunicação, ou seja, em decorrência das vivências trocadas entre sujeitos.

Em relação à educação ambiental voltada para a sustentabilidade, Brito (2012) ressalta que os espaços não formais de educação permitem ao aluno ser protagonista do próprio saber, desenvolvendo autonomia para investigar, analisar e classificar informações a ele disponibilizadas e assim fazer inferências construindo o próprio conhecimento. Assim, a educação ambiental proposta em tais ambientes permite a aquisição de qualidades e capacidades necessárias para a mudanças das atitudes relativas ao meio ambiente (TOZONI-REIS, 2006).

Pode-se verificar ainda, na Tabela 2, que a escola foi citada por apenas 10,6\% dos alunos em relação a ter sido ela a fonte do conhecimento deles sobre a temática, fato que indica a necessidade da inserção de abordagens sobre sustentabilidade e práticas sustentáveis para os anos iniciais do Ensino Fundamental. A Base Nacional Comum Curricular (BRASIL, 2017) apresenta enfoque sobre a inserção da temática sustentabilidade e práticas sustentáveis para o ensino de ciências, para quinto ano das séries iniciais, propondo estudos voltados a identificar recursos naturais, suas características e formas sustentáveis de utilizá-los. O documento sugere, ainda, envolver as habilidades, reconhecer e debater ações conjuntas como práticas sustentáveis, a fim de solucionar as questões relacionadas aos danos ambientais causados pelos hábitos de consumo humano. 
É importante destacar o processo de alfabetização científica na educação formal, tendo como objetivo a inclusão das Ciências da Natureza nos currículos escolares, para possibilitar aos alunos uma cultura científica que lhes permita compreender o funcionamento da natureza e a influência dos avanços tecnológicos na vida das pessoas (POZO e CRESPO, 1998). Com isso, entende-se que a escola tem papel fundamental para o desenvolvimento do ensino e da aprendizagem na construção de um sujeito crítico, reflexivo e participativo.

Ainda acerca dos resultados elucidados na tabela acima, podemos evidenciar que apenas $10,6 \%$ dos alunos entraram em contato com informações sobre sustentabilidade em livros e revistas. Esse resultado chama atenção, pois contraria o que comumente ocorre dentro do cenário educacional. Por vezes, professores empregam livros, sobretudo livros didáticos, como meio exclusivo para pesquisa bibliográfica, o que, conforme Sariego, (2007), não é a melhor opção quando se trata de questões relacionadas ao meio ambiente. $\mathrm{O}$ mesmo autor defende que estes materiais "reproduzem uma prática autoritária, descrevem o ambiente de forma abstrata, mascarando os calamitosos problemas ambientais, tanto por apresentar os seus conhecimentos de forma compartimentalizada como pela falta de uma proposta unificadora quanto à Educação Ambiental" (SARIEGO, 2007, p. 01).

Por outro lado, as revistas, embora possuam um caráter comercial, isto é, sejam escritas de forma a conquistar o público leitor, possuem diversas potencialidades voltadas à Educação Ambiental, a saber: as revistas possuem conhecimento mais atualizados; os temas abordados são bastantes específicos e trazem uma ampla problematização; a forma escrita é de caráter interdisciplinar, o que favorece o amplo entendimento das questões ambientais (SARIEGO, 2007). Assim, faz-se necessário o uso de recursos que vão além de livros didáticos, tanto por professores quanto por alunos, ao buscar informações sobre questões ambientais.

Em relação ao entendimento dos discentes quanto à sustentabilidade, os resultados são apresentados na Tabela 3.

Tabela 3 - Frequência das respostas dos alunos de anos iniciais sobre o significado de sustentabilidade

\begin{tabular}{c|c}
\hline Alternativas & Percentual \\
\hline Tornar sustentável o meio ambiente & 31,1 \\
\hline Sustento físico do corpo. Ato de alimentar-se & 29,0 \\
\hline Ação verbal. O ato de fazer em si algo & 15,5 \\
\hline Construção de moradias & 2,2 \\
\hline Não soube responder & 22,2 \\
\hline Subtotal & $\mathbf{1 0 0}$
\end{tabular}

Fonte: Silveira et al. (2021). 
Os resultados apresentados na tabela acima evidenciam que $31,1 \%$ dos alunos acreditam que sustentabilidade é tornar o meio ambiente sustentável por meio da preservação, equilíbrio do meio ambiente, manutenção de plantas e animais, isto é, cuidado com a flora e a fauna, bem como, redução e reciclagem do lixo.

Essa concepção relatada pelos alunos está em consonância com o entendimento de Guisso e Baiôco (2000) ao afirmarem a necessidade de a educação assumir conscientemente as condições de existência, a fim de exercitar a idoneidade para decidir os melhores caminhos ao desenvolvimento sustentável do mundo, com aprendizados que possibilitem refletir criticamente sobre o cotidiano em favor do meio ambiente, uma vez que a ação do homem é fator crucial na promoção da sustentabilidade. Ou seja, é necessário estimular os alunos para um cuidado com o meio ambiente, e nesse sentido essa categoria explicita a preocupação que as crianças têm com a natureza.

Evidencia-se, nas respostas, a categoria "sustento físico do corpo e o ato de alimentarse" $(29 \%)$, como conceitos de sustentabilidade. A concepção prévia dos alunos em relação à sustentabilidade está concentrada também no sentido de sustento do corpo humano, sem menção do real significado da palavra. De acordo com a Língua Portuguesa, dicionário Michaelis, "o termo sustentar provém de amparar, dar ou receber alimentos, condições materiais ou cuidados fundamentais à manutenção da vida, garantir alimentação a quem realiza trabalho pesado" (MICHAELIS, 2020).

As respostas dos alunos provavelmente estão relacionadas ao entendimento social de seu cotidiano, como evidenciado anteriormente na Tabela 2 , dando sentido à vida individual ou em conjunto, que pode gerar uma problemática em relação à conceituação de sustentabilidade, pois a palavra sustentar pode ser erroneamente confundida com as necessidades de satisfações dos indivíduos, como compras de alimentos, roupas, objetos, e até mesmo no hábito da caça em outras espécies, demostrando que possíveis hábitos de consumo contradizem o conceito sustentável necessário para a preservação do planeta.

Houve um percentual de 22,2\% dos alunos que não soube responder tal questionamento. Esse resultado parece estar diretamente relacionado ao fato de muitos alunos não terem sequer escutar falar no termo sustentabilidade, conforme apontam os resultados da Tabela 1. Assim, esses alunos não conseguiram formular concepções estruturadas acerca da sustentabilidade, em parte porque o meio em que vivem e as discussões a respeito parecem não ter corroborado em fornecer subsídios para isso. Diante do exposto, fica evidente a necessidade de aproximar os 
conteúdos de ciências ao contexto social, o que viabiliza ao discente encontrar sentindo no que estuda e o prepara para a diversidade da vida (SOUZA, 2015). Lorenzetti e Delizoicov (2001), propõem uma alfabetização científica em ensino de ciências que não enfatize a formação de futuros cientistas, mas que seja capaz de fornecer subsídios para que os alunos compreendam e discutam os significados dos assuntos científicos e os apliquem em seu entendimento de mundo. Logo, é importante que os alunos compreendam a sustentabilidade e possam aplicá-la em suas ações diárias, favorecendo a preservação do planeta.

Ao serem questionados sobre exemplos de práticas sustentáveis, os alunos tiveram a oportunidade de citar distintas possibilidades. Os resultados obtidos a partir disso são encontrados na Tabela 4.

Tabela 4 - Frequência das respostas dos alunos de anos iniciais acerca de três exemplos sobre práticas sustentáveis

\begin{tabular}{l|c}
\hline \multicolumn{1}{c|}{ Categorias } & Percentual \\
\hline $\begin{array}{l}\text { Processos da natureza (Reciclagem/Adubos/Cuidar do Meio Ambiente/Cuidar da } \\
\text { natureza/Preservar/Não poluir/ Não desmatar) }\end{array}$ & 23,7 \\
\hline $\begin{array}{l}\text { Práticas ambientais (Plantar/Separar o lixo/Reutilizar/Apagar a luz/Não usar sacola plástica/ } \\
\text { adubar o solo/ Comer o que colhe) }\end{array}$ & 22,7 \\
\hline Sustento familiar e/ou trabalho & 13,4 \\
\hline Elementos na natureza (Água/tronco/raiz/energia/árvore/ambiente) & 8,8 \\
\hline Exemplos de sustentabilidade (Energia eólica/ Sacola Reutilizável/ Coleta seletiva) & 6,6 \\
\hline Sustentação do corpo & 2,2 \\
\hline Outros elementos & 5,5 \\
\hline Equívocos (Desmatar) & 1,1 \\
\hline Não citaram exemplos & 16,0 \\
\hline \multicolumn{1}{c|}{ Total } & 100,0 \\
\hline
\end{tabular}

Fonte: Silveira et al. (2021).

Os resultados demonstram que os alunos enfatizaram os processos da natureza $(23,7 \%)$, práticas ambientais $(22,7 \%)$, e sustento familiar $(13,4 \%)$, o que evidencia uma concepção associada ao desenvolvimento sustentável voltada para questões ambientais, sociais e econômicas. Sinaliza-se aqui que o conceito de desenvolvimento sustentável, de acordo com o Relatório Brundtland (1987), é aquele que satisfaz as necessidades do presente sem comprometer a capacidade das futuras gerações em satisfazer suas próprias necessidades (WCED, 1987).

Segundo Wheeler (2000), são descritos três sistemas de desenvolvimento sustentável: econômico, social e ambiental. Cada um deles é integrado aos seus subsistemas e, por isso, é possível falar sobre sistema de ideias inter-relacionadas. Com isso, entende-se que as concepções dos alunos são formadas por meio de suas observações, interpretações e 
perspectivas ao longo de seus conhecimentos, valores e vivências. Entretanto, Gadotti (2000), salienta que o capitalismo gerou uma negativa situação com relação à natureza, mediante o potencial destrutivo gerado pelo sistema de produção de bens, tendo como resultado um modelo de desenvolvimento social marcado pelo lucro e exploração dos recursos naturais.

A partir desse cenário, é importante que as ações pedagógicas presentes no cotidiano escolar possam romper com esse ciclo que é extremamente danoso para o ambiente. A investigação realizada por Rezende e Bampi (2019) com professores que realizam práticas pedagógicas voltadas para a Educação Ambiental apontou que tais práticas contribuem para impulsionar mudanças de atitudes e conscientização sobre o meio ambiente. Dessa forma, fica evidente a relevância dessas ações para promover uma visão menos utilitarista e baseada no consumo excessivo, dando lugar a um entendimento mais empático com o local em que se vive. Os mesmos autores ainda relatam que, embora as práticas pedagógicas ambientais sejam essenciais na educação escolar, diversos são os entraves para que o professor consiga as inserilas no cotidiano, dentre os quais falta de tempo, de recursos humanos, materiais e financeiros.

Os resultados mostram também que $16 \%$ dos discentes ainda desconhecem o termo "práticas sustentáveis", o que evidencia a importância de um ensino de ciências no qual a natureza não seja apenas descrita ou conceituada e sim percebida de maneira a experienciar práticas sustentáveis, a fim de compreender a origem dos impactos ambientais.

Ainda, no decorrer da Tabela 4 é possível verificar que alguns discentes elencaram atitudes contrárias àquelas relativas à conservação do ambiente, equívocos como desmatar (1\%), o que leva a perceber a necessidade do desenvolvimento de atividades práticas voltadas para a área de ciências em educação ambiental. Perrenoud (2000) acrescenta que, nas situações de aprendizagem, é necessário o professor envolver os alunos em atividades de pesquisa, em projetos de conhecimento, pois estudos mostram que crianças que passam mais tempo em contato com áreas naturais apresentam um comportamento mais harmonioso, fantasiam mais, brincam melhor e têm uma melhor percepção do espaço em que vivem (GRAHN, 1994; TIRIBA, 2005). Diante do exposto, no âmbito escolar devem ser desenvolvidas ações que visem às questões ambientais, de modo a oportunizar transformações no conhecimento dos alunos, com propostas pedagógicas em relação à contextualização de práticas sustentáveis. Com isso, por meio da mudança de conceitos equivocados, os alunos poderão potencializar a sua responsabilidade individual e torná-la coletiva através de sua aprendizagem (ALBUQUERQUE, 2013). 
Assim, Carvalho (2001) argumenta que a prática educativa e reflexiva viabiliza a observação e a compreensão na consolidação de uma ética que expressa a sensibilidade ecológica voltada para a construção de uma cidadania ambientalmente sustentável.

A Tabela 5 apresenta os resultados referentes ao questionamento realizado aos alunos, quando solicitado quais das palavras fornecidas a eles estavam ou não associadas à sustentabilidade. Foi explicado aos participantes que poderiam assinalar mais de uma opção, o que implica em percentuais superiores a $100 \%$.

Tabela 5 - Frequência das respostas dos alunos de anos iniciais à identificação de palavras associadas à sustentabilidade como sendo verdadeiras ou falsas

\begin{tabular}{l|c|c}
\hline Palavras atribuídas & $\begin{array}{c}\text { Palavras associadas como } \\
\text { verdadeiras }\end{array}$ & Palavras associadas como falsas \\
\hline Meio ambiente & 91,1 & 8,9 \\
\hline Cuidados com meio ambiente & 91,1 & 8,9 \\
\hline Reciclagem & 86,7 & 13,3 \\
\hline Captação de água da chuva & 82,2 & 18,8 \\
\hline Coleta seletiva & 82,2 & 18,8 \\
\hline Preservação & 80,0 & 20,0 \\
\hline Plantio de florestas & 77,8 & 22,2 \\
\hline Apagar a luz & 68,9 & 32,1 \\
\hline Composteira & 22,2 & 78,8 \\
\hline Morte de abelhas & 20,0 & 80,0 \\
\hline Destruição ambiental & 20,0 & 80,0 \\
\hline Poluição & 20,0 & 80,0 \\
\hline Desmatamento & 17,8 & 83,2 \\
\hline Pobreza & 13,3 & 87,7 \\
\hline Agrotóxicos & 8,9 & 91,1
\end{tabular}

Fonte: Silveira et al. (2021).

$\mathrm{Na}$ Tabela 5 verificou-se que os alunos assinalaram com maior percepção palavras associadas à sustentabilidade, dentre as quais se destacam, meio ambiente $(91,1 \%)$, reciclagem $(86,7 \%)$, coleta seletiva $(82,2 \%)$ e preservação $(80 \%)$, o que demonstra que para esses alunos, o conceito de sustentabilidade está atrelado às questões ambientais presentes na sociedade (MELO; BRENNAND, 2004). Essas questões ambientais têm sido ressaltadas diariamente na sociedade, enfatizadas principalmente nas mídias e também nas escolas. Nesse sentido, é importante aproveitar as percepções trazidas às salas de aula pelos alunos, as quais advêm dos meios de comunicação visto que, crianças bem instruídas diante das questões ambientais tendem a ser adultos preocupados com o meio ambiente e que, terão condições de compartilhar os conhecimentos construídos na escola.

Desta maneira, tais conhecimentos devem ser percebidos pelo educador, pois há temáticas ainda pouco exploradas, como a reciclagem, por exemplo. De acordo com Caron 
(2011), apesar dessa temática ser muito comentada ela é pouco trabalhada, afinal o problema com o lixo não acaba quando é colocado para fora de casa, pois é neste momento que ele começa, visto que muitas cidades não possuem lugares apropriados, como aterros sanitários, onde o lixo é depositado adequadamente, para evitar uma possível proliferação de animais transmissores de doenças.

De acordo com o trabalho desenvolvido por Godoy et al. (2008), os alunos são capazes de identificar os principais problemas ambientais, mas não de forma mais ampla, com apropriação do conteúdo. Essa condição fica evidente ao se observar os resultados obtidos na pesquisa desenvolvida para este estudo, nos quais os alunos inferiram que as palavras agrotóxicos $(91,1 \%)$, pobreza $(87,7 \%)$, desmatamento $(80 \%)$, destruição ambiental $(80 \%)$ e morte das abelhas (80\%) não estão associadas à sustentabilidade, porém esses aspectos estão relacionados às questões de intervenção do homem no meio ambiente.

Constatou-se, pela resposta dos alunos, que eles não têm dimensão do impacto das questões ambientais quando se analisa o lado social do problema, fato que revela a necessidade de os professores explorarem essa temática através da educação ambiental. Leff (2003) defende que compete ao educador buscar e promover mudanças de caráter teórico-pedagógicas a partir da integração da temática ao cotidiano do aluno, o que contribui para a construção de uma visão mais ampla em relação à problemática ambiental.

Silva et al., (2014) argumentam que o simples fato de alguém existir gera algum tipo de impacto ambiental e social. A sustentabilidade não tem foco individual, mas sim coletivo. Devese considerar todo o conjunto complexo em que o homem está inserido, abandonando uma consciência individualista em busca de uma coletiva. Em contrapartida, Guimarães (1995) salienta que o homem é analisado através de seu comportamento incorreto em relação à natureza. Diante disso, o educador deve tomar o cuidado de não desenvolver no aluno a visão do homem como o centro, "o ser superior", que domina e se apropria da natureza, proporcionando o desenvolvimento da preservação do meio ambiente através da exclusão do homem, pois o antropocentrismo pode ser um obstáculo epistemológico para a compreensão da dinâmica ecológica da natureza.

Ainda sobre o questionário aplicado, na última atividade foi apresentada aos alunos uma coletânea com doze imagens, as quais foram retiradas da internet e pré-selecionadas pelos pesquisadores. Os alunos deveriam assinalar quais das imagens demonstravam atitudes/práticas saudáveis ao meio ambiente. 
Da mesma forma como na anterior, nessa questão também os alunos poderiam assinalar mais do que uma opção. Assim, ao serem calculadas as frequências percentuais, os valores ultrapassam os 100\%. Esses resultados são apresentados separadamente nas Tabelas 6 e 7 . Na Tabela 6 há asas imagens associadas às práticas sustentáveis e os percentuais de respostas, e na Tabela 7 as imagens associadas às atitudes não saudáveis ao meio ambiente o seu respectivo percentual de resposta. No questionário as imagens dos dois grupos foram apresentadas juntas aos alunos.

Tabela 6 - Frequência das respostas dos alunos de anos iniciais do ensino fundamental sobre o reconhecimento de imagens representantes de atitudes saudáveis ao meio ambiente

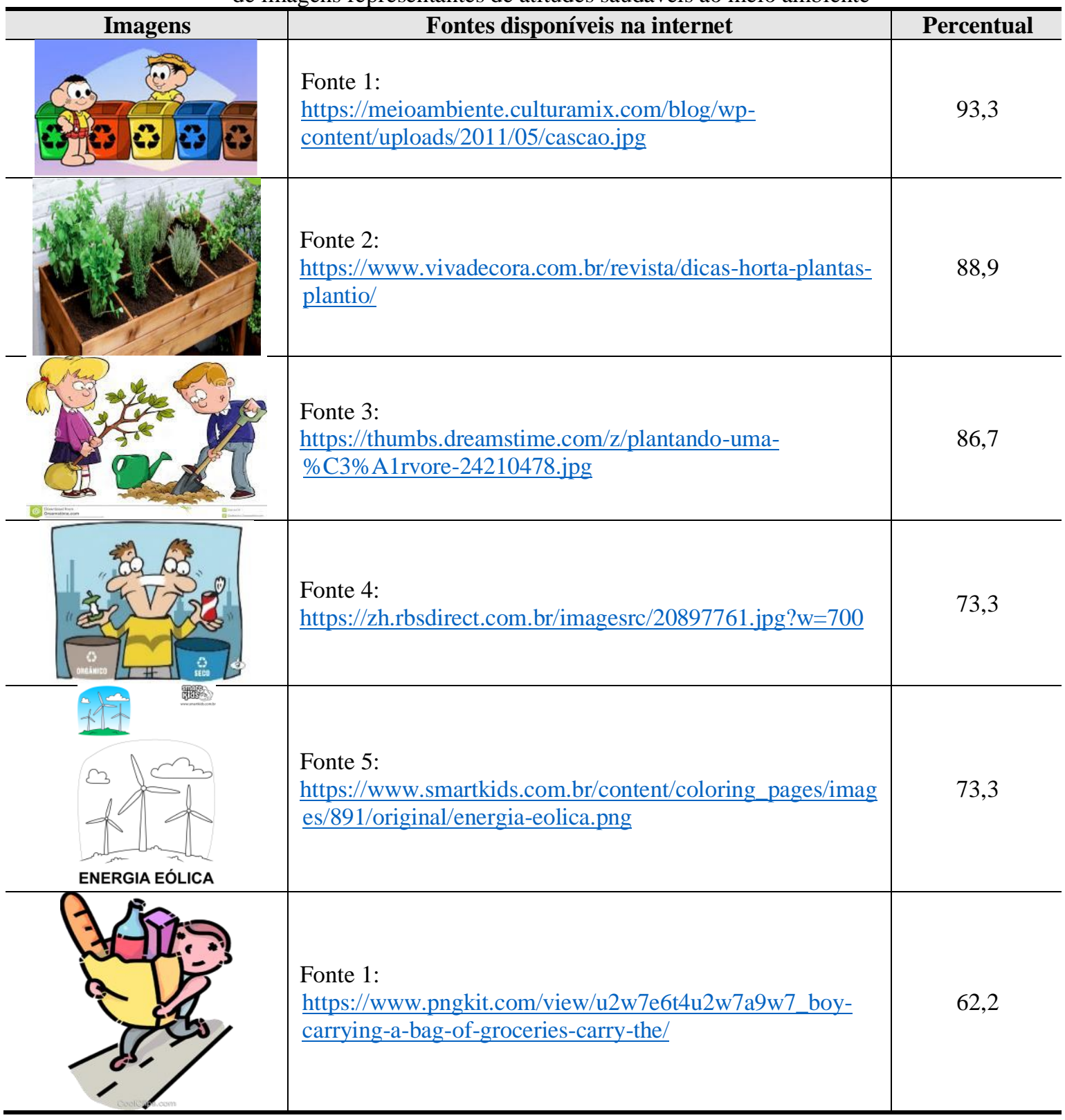

Fonte: Silveira et al. (2021). 
Tabela 7 - Frequência das respostas dos alunos de anos iniciais sobre o reconhecimento de imagens representantes de atitudes não saudáveis para ao meio ambiente

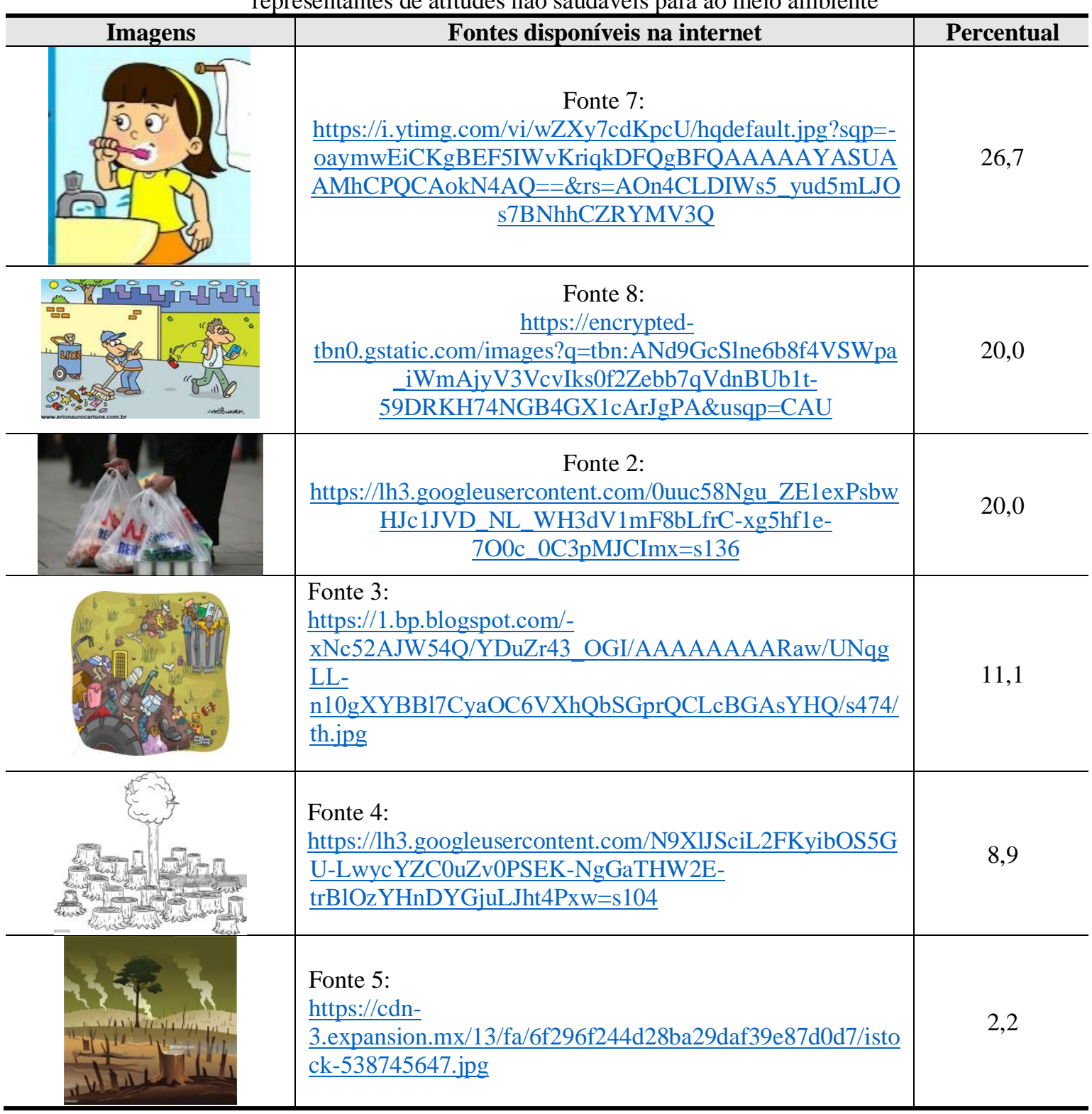

Fonte: Silveira et al. (2021).

Os resultados apresentados nas Tabelas 6 e 7 indicam a relação dos alunos com o meio ambiente e o papel deles como cidadãos diante das atitudes de práticas sustentáveis, as quais devem ser compreendidas e analisadas a fim de adequar a elas as atitudes humanas.

Assim, percebe-se que 93,3\% dos alunos enfatizaram a importância da separação do lixo, o que é importante, já que o descarte correto dos resíduos ocasiona a diminuição de problemas ambientais e é uma atitude adequada à preservação da biodiversidade. Sobre isso Costa e Stamato (2009) afirmam que a reciclagem pode reduzir a progressiva acumulação de lixo de diversas ordens, como por exemplo o papel, que evitaria o corte de árvores, as emissões de gases de metano e carbônico, as agressões ao solo, ar e água. 
Sobre o resultado obtido na questão das imagens verifica-se também que os estudantes demonstraram saber sobre a importância de plantar (86,7\%), sendo possível destacaras hortas $(88,9 \%)$, as quais funcionam como um espaço de criação, de incentivo e aprendizagem de matérias abordadas em âmbito escolar, bem como possibilitam ao aluno conectar-se à natureza e identificar seu papel como indivíduo. A utilização de hortas é uma forma de facilitar a participação e a troca de informações dos alunos no seu processo de construção do conhecimento (SOUZA, 2007).

Contudo, mesmo possuindo percepções coerentes quanto à temática, ainda foram sugeridas como atitudes saudáveis ao meio ambiente o uso da torneira aberta $(26,7 \%)$, jogar lixo no chão (20\%) e desmatamento (8,9\%). Jacobi (2005) argumenta a dependência e falta de responsabilidade da população em decorrência da desinformação bem como o déficit de práticas em conjunto voltadas à participação e envolvimento da sociedade, atitudes que possibilitariam uma nova cultura, baseada na motivação e na coparticipação na gestão do meio ambiente.

\section{CONSIDERAÇões FinAIS}

A sustentabilidade e as práticas sustentáveis são temas que permeiam o cotidiano atual diante do acelerado processo de crescimento populacional e consequente interferência antropológica no meio ambiente. Logo, esses são assuntos que vêm ganhando destaque também em diversas mídias, e não apenas no espaço escolar. Para tanto, neste trabalho buscou-se investigar e analisar as percepções de estudantes de quintos anos do Ensino Fundamental sobre sustentabilidade e sobre práticas/atitudes sustentáveis.

Por meio desse estudo foi possível perceber que a maioria dos alunos dos quintos anos do Ensino Fundamental da escola amostrada não reconhece a palavra sustentabilidade. Quando lembrado, esse termo foi acessado principalmente por meio das mídias ou através dos conhecimentos compartilhados por familiares. Ainda assim, a compreensão do termo sustentabilidade se dá de maneira inadequada, por vezes associado ao sustento do corpo ou sustento familiar, no pressuposto de fornecer recursos para a sobrevivência individual. Igualmente, termos como "compostagem de resíduos orgânicos" e "pobreza" são palavras às quais os alunos não associaram a sustentabilidade, demonstrando um conhecimento incipiente sobre a temática.

Já as práticas/atitudes sustentáveis são elementos aos quais as crianças estão mais familiarizadas, já que têm acesso a informações sobre a reciclagem, por exemplo, e práticas ambientais como o plantio de árvores. No entanto, há um percentual significativo de alunos que 
consideram escovar os dentes com a torneira aberta e jogar lixo no chão como atitudes responsáveis em relação ao meio ambiente, o que evidencia uma concepção confusa sobre práticas sustentáveis.

Assim, os resultados demonstram a necessidade da contextualização do tema sustentabilidade no ensino de ciências para anos iniciais, na ambição de modificar e/ou ampliar as informações que são percebidas antes mesmo de os alunos terem contato com os saberes escolares. Ademais, tais concepções servem como base para a construção de novos conhecimentos a partir dos saberes científicos vindouros das aulas de ciências.

Ao final deste estudo, sugere-se a implantação de estratégias didáticas voltadas para a temática sustentabilidade e práticas/atitudes sustentáveis, sobretudo nos anos iniciais do ensino fundamental, que levem em conta os saberes prévios dos estudantes, promovendo uma aprendizagem significativa, possibilitando, assim, um conhecimento científico mais voltado para a preservação, o manejo e o cuidado com o planeta.

\section{REFERÊNCIAS}

ALBUQUERQUE, Maria. Educação ambiental e EJA: Percepção dos alunos sobre o ambiente. 2013. Disponível em: http://www.revistaea.org/artigo.php?idartigo=1402 Acesso em: 20 de junho de 2021.

AUSUBEL, David Paul. Aquisição e Retenção de Conhecimentos: Uma Perspectiva Cognitiva. Lisboa: Plátano, 2003.

BARDIN, Laurence. Análise de conteúdo. São Paulo: Edições 70, 2011.

BRASIL. BASE NACIONAL COMUM CURRICULAR. Educação é a base. Ministério da Educação, 600p. 2017. Disponível em: http://basenacionalcomum.mec.gov.br/images/BNCC_EI_EF_110518_versaofinal_site.pdf. Acesso em: 15 de maio de 2020.

BRASIL. Constituição (1988). Constituição da República Federativa do Brasil. Brasília, DF: Senado Federal: Centro Gráfico, 1988.

BRASIL. Ministério da Educação. Conselho Nacional de Educação. Resolução CNE/CP n 2, de 15 de junho de 2012. Estabelece as Diretrizes Curriculares Nacionais para a Educação Ambiental. Diário Oficial da União, Brasília, DF, 18 jun. 2012.

BRINSMEAD, Thomas; HOOKER, Cliff. Complex systems dynamics and sustainability: conception, me-thod and policy. In: HOOKER, C. Handbook of the philosophy of science. North-Holland, Amsterdam, 2011. 
BRITO, Alberto Gomes. O Jardim Zoológico enquanto espaço não formal para promoção do desenvolvimento de etapas do raciocínio científico. 2012. 114 f., il. Dissertação (Mestrado em Ensino de Ciências) Universidade de Brasília, Brasília, 2012.

CARVALHO, Isabel Cristina de Moura. A Invenção ecológica. Porto Alegre: Editora da UFRGS, 2001.

CARON, Marisa Fernanda Raggio. Concepções prévias de estudantes do $1^{\circ}$ ano do Ensino Médio sobre Reciclagem. Disponível em: http://143.107.22.92/tce/disponiveis/1/1008/tce18112011-19542/publico/MarisaTCC.pdf. Acesso em: 17 de agosto de 2020.

COSTA, Vitor Vieira; STAMATO, Claúdia. Reciclagem de lixo doméstico, $\mathbf{5}^{\circ}$ Congresso Internacional de Pesquisa em Desing, Bauru - SP, p.1608 -1613, out. 2009.

DIAS, Genebaldo Freire. Educação Ambiental: princípios e práticas. 6.ed. São Paulo: Gaia, 2000.

GADOTTI, Moacir. A questão da educação formal/não-formal. Droit à l'education: solution à tous les problèmes sans solution? Institut International des droits de l'enfant, Sion, 2005.

GADOTTI, Moacir. Pedagogia da Terra. 6. ed. São Paulo: Peirópolis, 2000. 217 p.

GODOY, Carlos Eduardo Camargo et al. A aprendizagem baseada em problemas e a introdução de conceitos químicos nas aulas de ciências no Ensino Fundamental II. In: XIV Encontro Nacional de Ensino de Química, 2008, Curitiba. Anais... Curitiba: UFPR, 2008.

GOHN, Maria da Glória Marcondes. Educação não-formal e cultura política. São Paulo: Cortez, 2008

GRAHN, Patrik. The Importance of Green Urban Areas for People's Well-being. European Regional Planning, n. 56, p. 89 -112, 1994.

GUIMARÃES, Mauro. A dimensão ambiental na educação. São Paulo: Papirus, 1995.

GUISSO, Luana Frigulha.; BAIÔCO, Valdinéia Rodrigues Mantovani. A educação ambiental e o papel do educador na cultura da sustentabilidade. Disponível em: https://revistaea.org/pf.php?idartigo=2580 Acesso em: 11 de setembro de 2020 .

JACOBI, Pedro. Educação ambiental, cidadania e sustentabilidade. Cadernos de pesquisa, v.118, n. 3, p. 189-205, 2003. https://doi.org/10.1590/S0100-15742003000100008.

JACOBI, Pedro Roberto. Educação Ambiental: o desafio da construção de um pensamento crítico, complexo e reflexivo. Educação e Pesquisa, São Paulo, v. 31, n. 2, p. 233-250, maio/ago. 2005. https://doi.org/10.1590/S1517-97022005000200007

KATES, Robert Willian et al. Sustainability science. Science, v. 292, p. 641-642, 2001.

LAMBIN, Eric. Condições para a sustentabilidade dos sistemas humano-ambientais: informações, motivação e capacidade. Mudança Ambiental Global, v. 15, p. 177-180, 2005. 
LEFF, Enrique. Epistemologia ambiental. São Paulo: Cortez, 2001.

LEFF, Enrique. A Complexidade Ambiental. Tradução de Eliete Wolff. São Paulo: Cortez, 2003.

LEONARDI, Ariadne de Freitas et al. Análise de concepções alternativas de alunos dos anos iniciais acercados seres vivos. Revista educere et educare, v. 13, n. 30, nov/dez.2018. https://doi.org/10.17648/educare.v13i30.18665

LIBÂNEO, José Carlos. Pedagogia e pedagogos, para quê? 12. ed. São Paulo: Cortez, 2010.

LORENZETTI, Leonir; DELIZOICOV, Demétrio. Alfabetização científica no contexto das séries inicias. Ensaio - Pesquisa em Educação em Ciências, Belo Horizonte, v. 3, n. 1, jun. 2001.

MARIN, Andréia Aparecida et al. A educação ambiental num contexto de complexidade do campo teórico da percepção. Interciência. v. 28, p. 616-619, 2003.

MARQUES, Amanda Cristina Teagno Lopes.; MARANDINO, Martha. Alfabetização Científica, crianças e espaços de educação não formal: diálogos possíveis. Revista Educação e Pesquisa. São Paulo, v. 44. p.1-19, 2018.

MELO NETO, Francisco Paulo de; BRENNAND, Jorgiana Melo. Empresas socialmente sustentáveis: o novo desafio da gestão moderna. Rio de Janeiro: Qualitymark, 2004.

MICHAELIS. Moderno Dicionário da Língua Portuguesa. Disponível em:

http://michaelis.uol.com.br/busca?id=OWQE. Acesso em: 15 agosto de 2020.

MIGLIARI JÚNIOR, Arthur. Crimes Ambientais. São Paulo: Lex Editora, 2001.

MOREIRA, Marco Antonio. O que é afinal aprendizagem significativa? (after all, what is meaningful learning?) Aula Inaugural do Programa de Pós-Graduação em Ensino de Ciências Naturais, Instituto de Física, Universidade Federal do Mato Grosso, Cuiabá, MT, 23 de abril de 2010. Qurriculum, La Laguna, Espanha, 2012.

NEVES, Miranilde Oliveira. A importância da investigação qualitativa no processo de formação continuada de professores: subsídios ao exercício da docência. Revista Fundamentos, Piauí v.2, n.1, 2015.

PARASURAMAN, August. Marketing research, $2^{\mathrm{a}}$ ed. New York: Addison-Wesley Publishing Company, 1991

PERRENOUD, Philippe. 10 novas competências para ensinar - tradução Patricia Chittoni Ramos. Editora Artimed 2000.

POZO, Juan Ignacio; CRESPO, Miguel Ángel Gómez. Aprender y enseñar ciencias. Del conocimiento cotidiano al conocimiento científico. Ed. Morata SL. Madri, 1998.

RAVEN, Peter Hamilton. Ciência, sustentabilidade e a perspectiva humana. Science, v. 297, n.5583, pág. 954-958, 2002. 
REZENDE, Fernanda Shono da Silva Lopes; BAMPI, Aumeri Carlos. Práticas pedagógicas em Educação Ambiental na educação básica: dificuldades e potencialidades da inserção da temática nas escolas. Educação Ambiental em Ação, nº7, 2019. Disponível em: http://www.revistaea.org/artigo.php?idartigo=3597. Acesso em: 20 de junho de 2021.

SANTOS, Verônica Soares dos; MACHADO, Ana Carolina Ferreira; RIZZATTI, Ivanise Maria. A importância da Experimentação no ensino de ciências para o entendimento do ciclo da água: uma proposta para a educação infantil. Actio, Curitiba, v. 4, n. 3, p. 131- 145, set./dez. 2019

SARIEGO, José. Uso de revistas como material didático alternativo para a Educação Ambiental. Educação Ambiental em Ação, n. 22, 2007. Disponível em:

http://revistaea.org/artigo.php?idartigo=517. Acesso em: 20 de junho de 2021.

SILVA, Daniele Mercês et al. Saberes docentes e ensino de ecologia: uma investigação sobre a formação do pedagogo para o ensino de ciências. Revista Tecné, Episteme y Didaxis: TED. Año 2014, Número Extraordinario. ISSN Impreso: 0121-3814, ISSN web: 2323-0126 Memorias, Sexto Congreso Internacional sobre Formación de Profesores de Ciencias. Bogotá 08 al 10 de octubre de 2014.

SOUZA, Darklê Luiza et al. As abelhas como agentes polinizadores (The bees agentes pollinizer's) REDVET. Revista Electrónica de Veterinária, v. 8, n. 3, p. 03, mar., 2007.

SOUZA, Tadeu Teixeira de. O Letramento Científico e Práticas dos Professores de Biologia do Ensino Médio. 2015. 137f. Dissertação (Mestrado Profissional em Ensino de Ciências Exatas) - Centro Universitário Univates, Lageado - RS, 2015. Disponível em: https://www.univates.br/bdu/handle/10737/801 Acesso em: 10 de maio de 2020.

TIRIBA, Lea. Crianças, natureza e educação infantil. In: REUNIÃO ANUAL DA ANPEd, 29, 2006, Caxambu: Anais GT7. Disponível em:

https://www.anped.org.br/biblioteca/item/criancas-natureza-e-educacao-infantil Acesso em: 20 de junho de 2021

TOZONI-REIS, Marília Freitas de Campos. Temas ambientais como temas geradores: contribuições para uma metodologia educativa ambiental crítica, transformadora e emancipatória. Educar, Curitiba n.27, p.93-110. 2006.

WCED. Comissão Mundial sobre Meio Ambiente e Desenvolvimento: nosso futuro comum. Oslo: WCED, 1987. Disponível em: http://www.onu.org.br/rio20/documentos/ Acesso em: 15 de abril de 2020.

WHEELER, Keith. Introduction. In: WHEELER, K. A. e BIJUR, A. P. (Eds.). Education for a sustainable future. A paradigm of hope for the 21st century. New York (NY): Kluwer Academic, 2000. 


\section{APÊNDICE A - QUESTIONÁRIO SOBRE SUSTENTABILIDADE}

1. Você já ouviu a palavra sustentabilidade?

( ) Sim ( ) Não ( ) Não tenho certeza

2. Onde você já ouviu falar sobre sustentabilidade? Pode marcar mais de uma.

( ) Não ouvi falar ( ) Na televisão ( ) Na internet ( ) Em casa, com familiares ( ) Livros/Revistas ( ) Na escola ( ) Outros.

Onde?

3. Cite três exemplos do que você imagina serem práticas sustentáveis:

a)

b)

c)

4. Marque com $\mathrm{V}$ as palavras que você associaria à sustentabilidade e com $\mathrm{F}$ as palavras que não estão relacionadas à sustentabilidade:

\begin{tabular}{|c|c|c|c|}
\hline ) meio ambiente & ( ) poluição & ( ) destruição ambiental & ( ) preservação \\
\hline ) desmatamento & ) reciclagem & ) coleta seletiva & pobreza \\
\hline ) agrotóxicos & ) morte de abelhas & ) composteira & ) apagar a \\
\hline
\end{tabular}
meio ambiente

5. Marque com um x o quadrado com imagens que represente atitudes saudáveis com o meio ambiente:

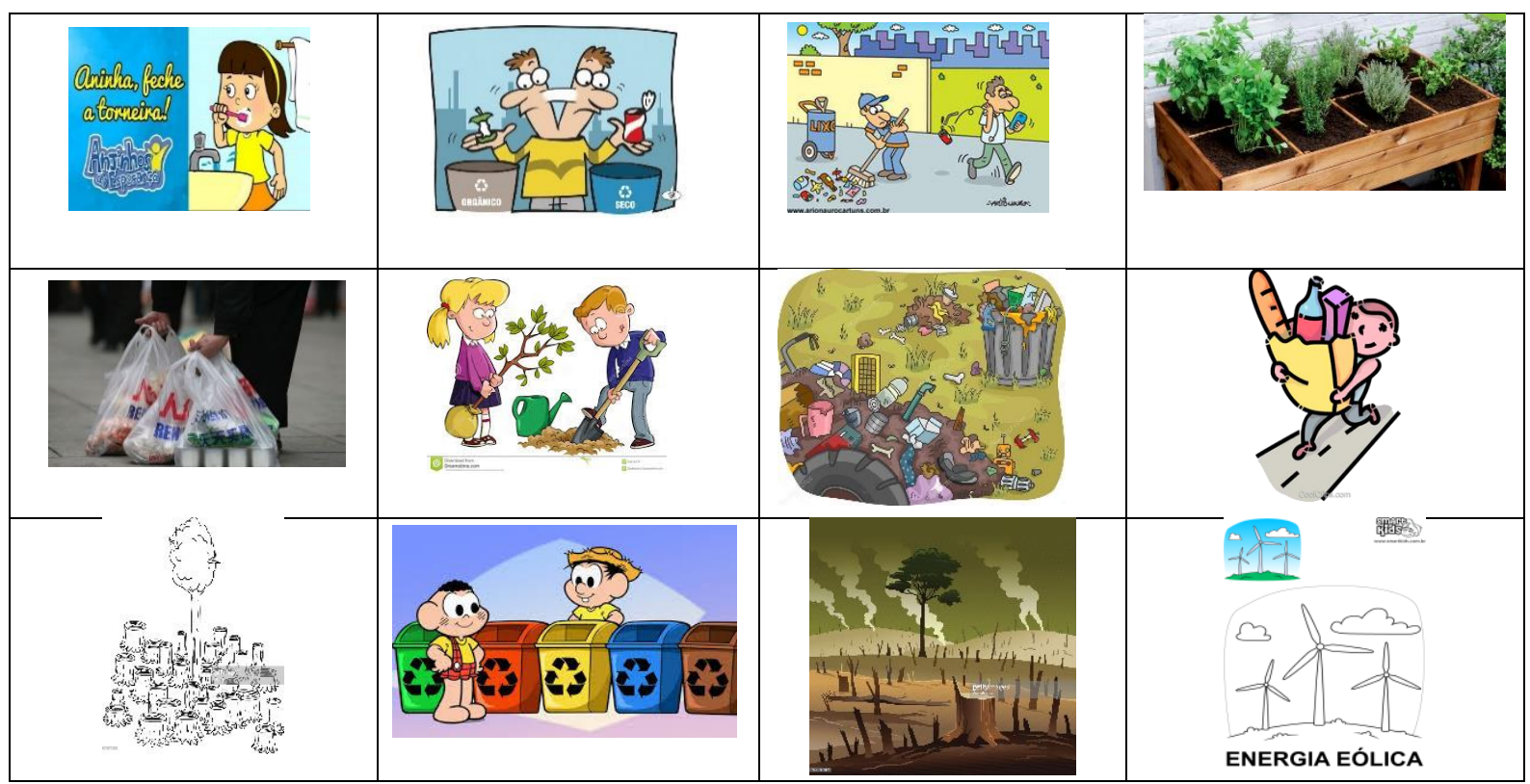

